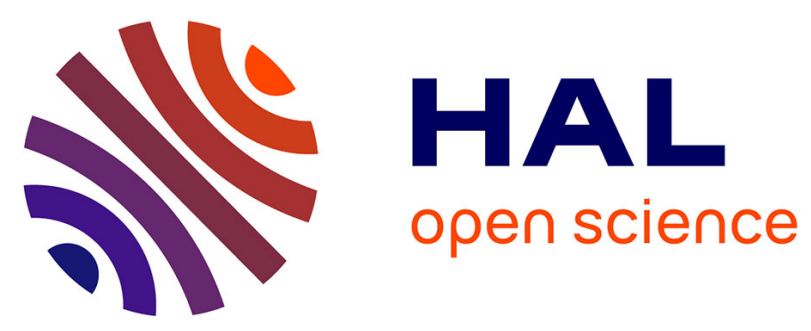

\title{
Harmonization of food categorization systems for dietary exposure assessments among European children
}

Melissa de Neve, Isabelle Sioen, Polly Boon, Claudia Arganini, Joanna Moschandreas, Jiri Ruprich, Lafay Lionel, Pilar Amiano, Davide Arcella, M Azpiri, et al.

\section{To cite this version:}

Melissa de Neve, Isabelle Sioen, Polly Boon, Claudia Arganini, Joanna Moschandreas, et al.. Harmonization of food categorization systems for dietary exposure assessments among European children. Food Additives and Contaminants, 2010, 27 (12), pp.1639-1651. 10.1080/19440049.2010.521957. hal-00644271

\section{HAL Id: hal-00644271 \\ https://hal.science/hal-00644271}

Submitted on 24 Nov 2011

HAL is a multi-disciplinary open access archive for the deposit and dissemination of scientific research documents, whether they are published or not. The documents may come from teaching and research institutions in France or abroad, or from public or private research centers.
L'archive ouverte pluridisciplinaire HAL, est destinée au dépôt et à la diffusion de documents scientifiques de niveau recherche, publiés ou non, émanant des établissements d'enseignement et de recherche français ou étrangers, des laboratoires publics ou privés. 


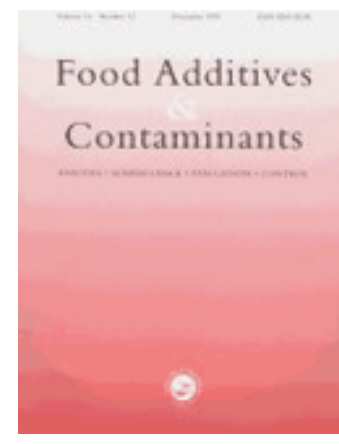

\section{Harmonization of food categorization systems for dietary exposure assessments among European children}

\begin{tabular}{|r|l|}
\hline Journal: & Food Additives and Contaminants \\
\hline Manuscript ID: & TFAC-2010-091.R1 \\
\hline Manuscript Type: & Original Research Paper \\
\hline Author: & O2-Sep-2010 \\
\hline Complete List of Authors: & De Neve, Melissa \\
& Sioen, Isabelle; Ghent University, Department of Public Health \\
& Boon, Polly; RIVM \\
& Arganini, Claudia; INRAN \\
& Moschandreas, Joanna \\
& Ruprich, Jiri; National Institute of Public Health \\
& Lionel, Lafay; AFSSA \\
& Amiano, Pilar \\
& Arcella, Davide; EFSA \\
& Azpiri, M \\
& Busk, Leif; SLV \\
& Christensen, Tue; DTU \\
& D'Addezio, Laura; INRAN - National Institute of Research on Foods \\
& and Nutrition, Statistics \\
& Fabiansson, Stefan; EFSA \\
& Hilbig, Annett; Reserach Institute of Child Nutrition \\
& Hirvonen, Tero; Evira \\
& Kersting, Mathilde; Research Institute of Child Nutrition, Germany \\
Koulouridaki, Stella \\
Liukkonen, Kirsi-Helena; Evira \\
Oltarzewski, Maciej; National Food and Nutrition Institute \\
Papoutsou, Stalo; Research and Education Institute of Child Health \\
Rehurkova, Irena; National Institute of Public Health \\
Ribas-Barba, Lourdes; Nutrition Research Foundation \\
Serra-Majem, Lluís; University of Barcelona, Community Nutrition \\
Research Group \\
Tornaritis, Michael; Research and Education Institute of Child \\
Health \\
\hline
\end{tabular}




\begin{tabular}{|c|c|}
\hline & $\begin{array}{l}\text { Trolle, Ellen; DTU } \\
\text { Van Klaveren, Jacob; RIVM } \\
\text { Verger, Eric; AFSSA } \\
\text { Walkiewicz, Alicja; National Food and Nutrition Institute } \\
\text { Westerlunc, Anna; SLV } \\
\text { De Henauw, Stefaan; Ghent University, Department of Public Healt } \\
\text { Huybrechts, Inge; Ghent University, Public health }\end{array}$ \\
\hline Methods/Techniques: & Exposure, Exposure assessment, Total diet, Survey \\
\hline Additives/Contaminants: & Lead, Metals - selenium, Colours \\
\hline Food Types: & Beverages, Cereals and grain, Cooked foods, Ingredients \\
\hline
\end{tabular}

\section{SCHOLARONE ${ }^{m}$ Manuscripts}




\section{Harmonization of food categorization systems for}

2 dietary exposure assessments among European

\section{3 children}

$4 \quad$ M. De Neve ${ }^{a}$, I. Sioen ${ }^{a^{*}}$, P.E. Boon ${ }^{b}$, C. Arganinic ${ }^{c}$, J. Moschandreas ${ }^{d}$, J. Ruprich ${ }^{e}$, L. Lafay ${ }^{f}$, P.

5 Amiano $^{g}$, D. Arcella ${ }^{h}$, M. Azpiri ${ }^{9}$, L. Busk', T. Christensen', L. D’Addezio ${ }^{\text {c }}$, S. Fabiansson ${ }^{\text {h }}$, A.

6 Hilbig $^{k}$, T. Hirvonen', M. Kersting ${ }^{k}$, S. Koulouridaki ${ }^{d}$, K-H. Liukkonen', M. Oltarzewskim ${ }^{m}$, S.

7 Papoutsou $^{n}$, I. Rehurkova ${ }^{\text {, }}$, L. Ribas-Barba ${ }^{\circ}$, L. Serra-Majem ${ }^{\circ}$, M. Tornaritis ${ }^{n}$, E. Trolle , J.D.

$8 \quad V^{2}$ Kan Klaveren ${ }^{b}$, E. Verger ${ }^{\dagger}$, A. Walkiewicz ${ }^{m}$, A. Westerlund', S. De Henauw ${ }^{a}$ and I.

9 Huybrechts $^{a}$

${ }^{a}$ Department of Public Health, Ghent University, Belgium; ${ }^{b}$ National Institute for Public Health and the Environment (RIVM), The Netherlands; ${ }^{c}$ Istituto Nazionale di Ricerca per gli Alimenti e la Nutrizione, INRAN (National Institute for Research on Food and Nutrition), Italy; ${ }^{d}$ Department of Social Medicine, Faculty of Medicine, University of Crete, Greece; ${ }^{e}$ Department of Food Safety and Nutrition, National Institute of Public Health, Czech Republic; ${ }^{f}$ Agence Française de Sécurité Sanitaire des Aliments (AFSSA), France ; ${ }^{9}$ Public Health Division of Gipuzkoa, Basque Covernement, San Sebastian, CIBER Epidemiología y Salud

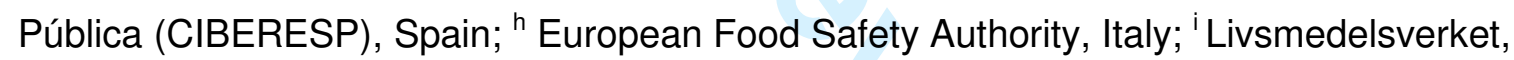
NFA (National Food Administration), Sweden; j Department of Nutrition, National Food Institute, Technical University of Denmark, Denmark; ${ }^{\mathrm{k}}$ Research Institute of Child Nutrition, Rheinische Friedrich-Wilhelms-Universitaet Bonn, Germany; 'Risk Assessment Unit, Finnish Food Safety Authority, Finland; ${ }^{\mathrm{m}}$ National Food and Nutrition Institute, Poland; ${ }^{\mathrm{n}}$ Research and Education Institute of Child Health, Cyprus; ${ }^{\circ}$ Fundación para la Investigación Nutricional (Nutrition Research Foundation, Science Park of the University of Barcelona), Spain

${ }^{*}$ Corresponding author. Email: Isabelle.Sioen@ugent.be 


\section{Abstract}

27 Within the European project called EXPOCHI (Individual food consumption data and exposure assessment studies for children), 14 different European individual food consumption databases of children were used to conduct harmonised dietary exposure assessments for lead, chromium, selenium and food colours. For this, two food categorisation systems were developed to classify the food consumption data in such a way that these could be linked to occurrence data of the considered compounds. One system served for the exposure calculations of lead, chromium and selenium. The second system was developed for the exposure assessment of food colours. The food categories defined for the lead, chromium and selenium exposure calculations were used as a basis for the food colour categorisation, with adaptations to optimize the linkage with the food colour occurrence data. With this work, an initial impetus was given to make user-friendly food categorisation systems for contaminants and food colours applicable on a pan-European level. However, a set of difficulties were encountered in creating a common food categorisation system for 14 individual food consumption databases that differ in type and number of foods coded and in level of detail provided about the consumed foods. The work done and the problems encountered in this project can be of interest for future projects in which food consumption data will be collected on a pan-European level and used for common exposure assessments.

Keywords: exposure assessment; children; Europe; food categorisation; EXPOCHI; food colours; lead; selenium; chromium

\section{Short title: Harmonized food categorisation systems}




\section{Introduction}

In the area of chemical food safety, food categorisation systems are used to link food consumption data with occurrence data of adverse chemicals present in foods, such as additives and contaminants. Such food categorisation systems are needed since occurrence data and food consumption data are often not available at the same level of detail.

Food consumption data are mostly collected for different purposes (e.g. monitoring population intakes of a range of macro- and micronutrients). Broad food categorizations that are not at a very detailed level of food description may suffice for these purposes. However, in the field of food safety, occurrence data of e.g. additives and contaminants can be collected at a different level of detail (e.g. at food or ingredient level). Use of broad food categories may then hamper the linkage with food consumption data. For example, additives are often analysed or set in specific foods (sometimes at brand level) as described in regulations, whereas trace metals are often analysed in raw foods, such as milk, meat, etc. Linkage of these occurrence data to food consumption data requires a conversion of consumption levels at food level to that at the level of raw ingredient (Boon et al., 2009). In addition are contamination or concentration data (e.g. for food colours) in general overestimated when they are aggregated at broad food groups because trace elements for instance are in general measured in foods that are supposed to contain the element or to have a high content of this substance. Furthermore, the level of detail present in food consumption surveys may be limited since subjects cannot always provide all the required information of what they have consumed (definitely when retrospective dietary intake assessment methods were used). Obtaining detailed information among children is even harder as they have only a limited capacity to recall their own food intake and parents are often unable to know what their child consumed at school or in the kindergarten. Therefore food consumption data are often available without all the detailed information needed to perform exposure assessments, what will result in an increase of the uncertainty in the resulting exposure outcome.

To link food consumption and occurrence data to assess the exposure to chemicals present in food, often foods consumed and those analysed are categorised in such a way that the most optimal link between both databases is established. Different categorisation systems are available for this, such as the categorisation system described in the SCOOP Tasks Report 3.2.11 (European Commission 2004) used to assess the exposure to different mycotoxins and the Concise European Food Consumption Database developed by the European Food Safety Authority (EFSA) (EFSA 2008), which has been used to assess the exposure to numerous chemicals, such as ochratoxin A (EFSA, 2006), arsenic (EFSA, 2009b), cadmium (EFSA 2009c) and lead (EFSA 2010). 
Food categorisation is a crucial activity to allow for processing of food consumption data, because it is not possible to interpret dietary data without aggregating individual food items into food groups, either before (close-ended survey forms, e.g. food frequency questionnaire) or after (open-ended forms, e.g. diary) the collection of food consumption data. Categorisation of food items implies the identification of foods and their characteristics in order to put the most similar items in the same category of the developed food categorisation system (Turrini 1999; Møller and Ireland 2008). The experience in the food data processing field has shown the necessity of developing different food categorisation systems related to the objectives of the study (Møller and Ireland 2008).

From November, $1^{\text {st }}, 2008$ until November, $30^{\text {th }}, 2009$, EFSA funded a research project aiming to create a relational network of different individual European food consumption databases of children (aged 1 to 14 years) and to perform dietary exposure assessment studies. Within this project, called EXPOCHI (Individual food consumption data and exposure assessment studies for children), fourteen individual food consumption databases representative for diverse regions/countries within Europe were harmonized in order to use the consumption data for four specific exposure assessment studies, i.e. for lead, chromium, selenium and a set of food colours. In total, 14 partners covering 13 European countries participated in the project. Food consumption data was derived from 24-h dietary recalls and dietary records. More information about the consortium, rationale, methods and design of this project can be found in a separate paper (Huybrechts et al. 2010).

Within the project, the different scientific partners provided the food consumption databases, whereas EFSA was responsible for the occurrence databases of the substances under study. To be able to conduct the requested exposure assessment studies in a standardized way, the 14 different consumption databases were harmonised by categorising all food items in common food groups. To optimize and harmonize the food linking in the EXPOCHI project, a food categorization manual was made. With the use of the manual, a standardised procedure of linking different European consumption databases with one European occurrence database per compound was established. Two food categorisation systems were developed within the project: one for the exposure assessments to lead, chromium and selenium and a second one for the food colours. In this paper, both categorisation systems as well as the difficulties encountered are described and discussed.

\section{Materials and methods}

Two different food categorisation systems and manuals 
Within the EXPOCHI-project, it was the aim to conduct harmonised dietary exposure assessment in children living in different European countries. Therefore, procedures were developed so that all partners categorised their food items in a standardized way. Two food categorisation systems were developed, both described in detail in two extensive manuals: an EXPOCHI-manual on Food Categorisation for (1) Lead, Chromium and Selenium and (2) Food Colours (freely available on request).

To apply the two food categorisation systems, first a list of unique food items as coded in the food consumption databases needed to be generated, containing - if available - details such as preparation, fat content (e.g. for milk), etc. Each food item in this food list was defined by a unique name (preferably in the local language as well as an English translation) and a unique food code. Starting from this food list, food items needed to be categorised in food groups, as defined in the food categorisation system by means of a data entry method described in the manuals. For this it is important that the characteristics of the foods as enclosed in the name of each food item are known in order to be able to categorise the foods correctly. During the categorisation, no difference was made between foods eaten at home or out-of-home, since those details were missing in most food consumption databases.

To develop the categorisation procedure and set up the manuals, preliminary samples of the 14 food lists obtained from the national food consumption databases and received from each partner in the EXPOCHI-project were explored to foresee problems and difficulties that partners would encounter during the categorisation work. These possible problems and difficulties were listed in the manuals and solutions were provided. Moreover, due to these food list samples, examples of food items from all geographical regions under study (e.g. specific local food items) could be included in the manuals. The manuals were continuously updated during the project to address all difficulties experienced during the categorisation work in the participating countries.

To illustrate the results of the food categorisation work, data from four different individual food consumption databases are presented covering a North-European country (Sweden), a West-European country (Belgium), a South-European country (Italy) and an East-European country (Czech Republic). For Sweden, the data were collected in 2003 by a nationwide food consumption survey conducted among children aged 3 to 4 and 7 to 13 years (EnghardtBarbieri et al. 2006). The Swedish consumption databases consisted in total of 1548 different food items. The Belgian food consumption data used in this project were collected in 20022003 from a representative sample of Flemish children aged 2.5 to 6.5 years (Huybrechts et al. 2008) and consisted of 1056 different food items. The Italian food consumption data were collected during the period of 2005-2006 for children aged 1 to 10 years (Leclercq et al. 
157 2009). The Italian food consumption databases consisted of 1530 different food items. In 158 Czech Republic, a food consumption survey was conducted between November 2003 and 1592004 with children aged 4 to 14 years (Ruprich et al. 2006). This database counted 515 160 different food items, primarily aggregated for the national total diet study focused mainly on 161 contaminants. For more details on the databases see Huybrechts et al. (2010).

\section{Lead, chromium and selenium}

The food categorisation system for lead, chromium and selenium was based on the food categorisation system described in the SCOOP Tasks report 3.2.11 (European Commission 2004). The groups mentioned in this SCOOP report are based on definitions from the Codex General Standard for Food Additives (GSFA) developed by the Codex Alimentarius Commission (Codex Alimentarius Commission 2009). The document describes the conditions under which permitted food additives may be used in all foods, whether or not they have previously been standardised by Codex. However, for the EXPOCHI-project, those definitions needed to be adjusted since foods in consumption databases are generally mentioned 'as eaten', whereas the definitions found in GSFA are mentioned 'as product in the food manufactory'.

\subsection{Main group and subgroups}

The lead, chromium and selenium categorisation system consisted of four hierarchical grouping levels: main group (MG), subgroup 1 (SG1), subgroup 2 (SG2) and subgroup 3 (SG3) and one descriptor: special code (SC). This structure is in accordance with Turrini (Turrini 1999), distinguishing two types of food coding variables: hierarchical codes and crosswise codes. Hierarchical codes aim at identifying the type of products (food group, subgroup), while crosswise codes are dedicated to the description of the characteristics (packaged or not, fresh or preserved, etc.).

The hierarchical categorisation process applied in this project was divided into two consecutive steps. Firstly, a main group was defined per food item in the food list. These main food groups and their definitions originated from the GSFA, describing 16 main groups (Codex Alimentarius Commission 2009). Two extra main groups 'Vegetarian meat and fish substitutes (MG17)' and 'Miscellaneous: foods that cannot be placed in categories (MG18)' were added to make it possible to categorise all food items occurring in the national food consumption databases. Table 1 lists all main groups defined in the food categorisation system for the lead, chromium and selenium exposure calculations. In the EXPOCHI manual, the GSFA definitions were reported, including extensions of the definitions to clarify the main 
192 groups more clearly. A short list of food items to be included in a certain food group and of 193 some to be categorised elsewhere illustrated these definitions. The first step was complete 194 when all food items had been assigned to one of the 18 main groups.

195 The second step consisted of categorization at subgroup level, which included a refining 196 of the main group categorisation by means of maximum three subgroup levels: SG1, SG2 197 and SG3. Figure 1 shows an example of subdividing MG 10 (Eggs and egg products) into 198 four different groups on the level of SG1 (10.1, 10.2, 10.3 and 10.4) and two different groups 199 on the level of SG2 when considering SG1 = 10.1 (i.e. fresh eggs): 10.1.1 and 10.1.2.

200 As is shown in Figure 1, the explanation per main group began with a brief summary 201 based on which it was decided to which subgroup a food item belonged. This was followed 202 by a diagram demonstrating the structure of all subgroups within one main group. Every 203 decision taken during the categorisation work was checked by the given definitions.

204 It was not always possible to categorise each food item at all three subgroup levels (SG1, 2052 and 3), due to two reasons: (1) not all main groups were subdivided into a second and third 206 subgroup level, and (2) not all national food consumption database provided enough detail 207 for each food item to be able to categorise it at a next (or lower), more detailed, subgroup 208 level. An illustration of this can be found in the example given in Figure 1, for SG2 of the 209 group 'fresh eggs' (10.1). Most food consumption databases did not include details on 210 whether eggs originated from indoor or outdoor reared eggs. Therefore, in those cases, the 211 categorisation stopped at the level of SG1.

\subsection{Special code}

An extra variable 'special code' (SC) was added as a descriptor for five main groups to add relevant information that was not included in the categorisation system based on MG, SG1, SG2 and SG3. This special code indicated the presence of a specific component (e.g. chocolate filling) or a physical state (e.g. powdered form), and was applied within the following five main groups: MG4 (fruits, vegetables, seaweed, nuts and seeds), MG7 (bakery wares), MG9 (fish, fish products, molluscs, cephalopods, crustacean and echinoderms), MG13 (foodstuff intended for particular nutritional use) and MG14 (beverages). If food items 222 the numbers in ascending order. A special code indicating the presence of soy in a food was 223 used for all main groups. Table 2 lists all special codes that were applied in the framework of 224 this project. 


\subsection{Link with occurrence data of lead, chromium and selenium}

During the project, it emerged that EFSA was not able to provide the occurrence data for the contaminants lead, chromium and selenium categorised according to the food categorisation system described in the SCOOP Tasks report 3.2.11 (European Commission 2004) but only according to the categorisation used in EFSA's Concise Food Consumption Database (EFSA 2008). Due to the huge number of occurrence data resulting from food testing in the different Member States (94,126 for lead, 23,750 for chromium and 47,858 for selenium), EFSA considered it inconvenient to reclassify all food descriptors in the occurrence database according to the SCOOP system. A link was therefore needed between the newly developed food categorisation system and that of EFSA's Concise European Food Consumption Database. Efforts were made to keep the anticipated major food contributors for lead, chromium and selenium in different food categories and, at the same time, to minimise the need for the reclassification of food descriptors. This resulted in a list of 42 communal food groups (Table 3) making it possible to link the food consumption data to the occurrence data. The main group and subgroup together with the special code were subsequently reorganized, as well as certain food items in such a way that the concentration data per communal food group were representative for the food items in those food groups.

\section{Food colours}

The food categorisation system as specified in the Council Directive 94/36/EC (European Commission 1994) was used to develop a system to classify all food items present in the different national food lists in order to perform dietary exposure assessments for food colours. This food colour classification system was tuned to the Flavourings, Additives and food Contact materials Exposure Task (FACET) project (http://www.ucd.ie/facet/). Occurrence data were provided by EFSA according to this categorization system.

Within the EXPOCHI-project, 41 different food colours were considered for exposure assessment. All, except lycopene, could be approached by one categorisation system based on 84 different food groups (Table 4), partly based on the Council Directive 94/36/EC and partly developed particularly for this project using the information of the FACET project (i.e. to further divide the category 'all other foodstuff' in more detailed categories) (European Commission 1994; Oldring et al. 2009). Of the 84 food groups, 16 were not taken into account within the EXPOCHI-project because the age group addressed in the exposure assessment to food colours was limited to children aged 1 up to 10 years (e.g. food groups like 'spirituous beverages', 'whisky', 'liqueurs' were irrelevant for this age group). The 68 food 
As stated, a separate food classification system was developed to classify foods for the lycopene exposure assessments. Since naturally occurring lycopene was not considered in the exposure analyses, the system included only food groups in which lycopene could be added as an additive. The food groups differed from those used for the other food colours on the level of aggregation. For example, lycopene is permitted in all types of bread, whereas for the other food colours, only malt bread was considered (see Table 4 and 5). Compared to the general food colour categorisation system, fewer food groups were needed to classify the food items for lycopene, since addition of lycopene is only permitted in a limited number of food groups (in total 33 food groups; see Table 5).

The food list including the main groups and subgroups of the food classification system for lead, chromium and selenium formed the starting point for the food colour classification system. Around half of the food items occurring in the food lists from the different EXPOCHI-partners belonged to a MG-SG combination that could be recoded as a whole in one single food colour group. For example, all food items in the food group 10.1 'Fresh eggs' (see Figure 1) belonged to the food colour group 0 'No food colours'. For the food items belonging to such a MG-SG-combination, the recoding into the food colour categorisation system could be performed automatically. In contrast, for the other part of the food items, the categorisation into the food colour groups was less straightforward, because food items within a similar MG-SGcombination did not belong to a similar food colour group. For example, the food items classified in 9.4.1 'Fish canned in oil' could belong to different food colour groups ( $F C G$ ): fish roe belongs to $F C G=16$; surimi belongs to $F C G=15$ and fish past belongs to $F C G=12$. This second step of the classification was performed according to guidelines included in the second categorisation manual.

\section{Results}

To illustrate the results of the food categorisation, data are shown for four of the 14 different countries: Belgium, Italy, Sweden and Czech Republic; and for two categorisation systems: the one for lead, chromium and selenium and the one for lycopene. A first important remark is the huge difference in the total number of food items entered in the different food consumption databases. The Czech databases contained the least number of food items ( $n=515$ ), followed by Belgium with 1056 different food items, Italy with 1530 and Sweden with 1548 food items. 
295 Table 3 shows the percentage per country of food items classified in each communal 296 food group for the lead, chromium and selenium exposure assessment. These results show 297 first of all that not all 42 communal food groups were needed to classify all food items. For 298 example, the communal groups 9 'Food supplements' and 34 'Other food for special dietary 299 uses' were used by two of the four countries, whereas group 26 'Other seafood' was only 300 used by Italy. Another difference was the percentage of food items in communal food group 2 301 'Vegetables'. This percentage was low for the Italian database compared to the other 302 countries, whereas the percentage of food items in group 3 'Waters' was high in Italy.

303 Results are also shown for the lycopene categorisation based on these four national 304 consumption databases (Table 5). Table 5 indicates that some food groups were not needed 305 by any of the four countries, such as groups 31 'Salmon substitutes' and 37 'Edible cheese 306 and edible casings'. The table also indicates that the percentage of food items to which 307 lycopene could be added differed considerably between the different databases, being 308 around $40 \%$ in Belgium, $31 \%$ in Italy and Sweden, and $22 \%$ in Czech Republic.

\section{Discussion}

In this paper, we described the food categorisation systems that were developed and applied to categorise 14 different food European consumption databases of children in the ages of 1 up to 14 years in order to prepare them for an exposure assessment study of three contaminants (lead, chromium and selenium) and a set of food colours. Although different food categorisation systems already exist (Møller and Ireland 2008), none could be applied without any modification. The work described in this paper illustrates that food categorisation systems can differ substantially depending on the compound under study, as described earlier (Turrini 1999): the food classification system developed for the contaminants differed on many aspects from the one developed for food colours (e.g. number of food groups, composition of food groups, number of food items per food groups).

The unique aspect of the food categorisation work performed in this project is that food items present in 14 different consumption databases for European children were categorised in a uniform way, making it possible to estimate the exposure to the chemicals under study in a uniform way. The food consumption databases used in this study were derived from different studies performed at the national / regional level. These databases differed on many aspects, including dietary assessment methods used and age ranges addressed. Another important difference, which affected the food categorisation (and consequently the resulting exposure calculations), was the way in which the primary dietary information was recorded and aggregated into food items and (sub) food groups. Due to this, the level of detail 
331 available of the foods present in the national / regional consumption databases differed 332 greatly. The examples used in this paper to illustrate the approach show that the different 333 food consumption databases differed much in the number of food items entered. For 334 example, the Italian and Swedish databases contained up to three times more food items 335 than the Czech database. The number of food items gives an indication of the level of detail 336 present in the database. For example, in some databases 'milk' can be the only entry, 337 whereas in other databases milk can be entered as 'milk, skimmed', 'milk, semi-skimmed' 338 and 'milk, whole'. Moreover, some food consumption databases contained details as brand 339 names (e.g. of confectionary), additives (e.g. yoghurt with or without sugar), etc. whereas 340 others did not. In fact, the attention paid either to specific food categories (e.g. supplements) 341 or to specific food components could affect the level of food description for the corresponding 342 groups. An additional remark concerns whether the transformation from composite food to 343 ingredients was performed or not. This operation could lead to vary the number of food 344 items. Overall, the more details available, the better and more detailed the categorisation 345 work could be performed.

346 To address the heterogeneous databases, two detailed manuals were developed, which 347 contain explanations and examples aiming to minimize the chance of misclassifications. 348 Difficulties during the project were discussed, resulting in updated version of the manuals. 349 These manuals address many differences in food items entered in national / regional 350 databases and can be very valuable when developing food categorisation systems to be 351 used in pan-European food consumption surveys. The development of such a food 352 consumption survey is one of EFSA's long-term objectives (EFSA, 2009).

353 To be able to link the categorised food consumption data with the lead, chromium and 354 selenium occurrence data received from EFSA, foods categorised according to the 355 hierarchical food categorisation system were generalised to 42 communal groups. During 356 this process, certain details on the foods entered in the different regional/national food 357 consumption databases were inevitably lost. Due to this, the link between the foods 358 consumed and those analysed will not be optimal, affecting negatively the representativity of 359 the ensuing exposure results. It is therefore important, for an optimal exposure result, that 360 both the food consumption and occurrence data are categorised at the highest level of detail 361 possible. In practice however, often either the consumption data or occurrence data are 362 categorised at a level that makes an optimal link not feasible. During the interpretation of the 363 exposure results obtained with such data, this should be taken into account. If for instance 364 the level of coding is too low there is a danger of assuming that all foods within that category 365 contain the highest level. Alternatively it could be assumed that all foods contain average 366 levels and so missing the true high-level individual. 


\section{1}

Also the food categorisation system developed for the exposure assessments to food colours, started from the detailed, hierarchical system developed based on the food categorisation system described in the SCOOP Tasks report 3.2.11 (European Commission 2004). However, the food groups needed to be recoded to the groups specified in the Council Directive 94/36/EC (European Commission 1994). In the first step, scripts could be used to reclassify automatically about half of the food items in the food lists from the hierarchical system to the groups of the food colour system. This was a time-saving procedure and it reduced the chance of mistakes (like typing errors).

Next, it should be noted that the precision of matching occurrence and consumption categories can have a major impact on the uncertainties introduced into the model. For the food colour exposure assessment, the most important source of uncertainty was the use of 'maximum permitted level' data in the worst case scenario, resulting in an overestimation of the exposure, also due to the use of very broad food groups. Also for the other components (lead, chromium and selenium), it is very likely that the exposure was overestimated due to the use of broad food groups. How large this overestimation is, is difficult to predict, since no information on the specific foods that were analysed was available. However, the approach used in this project is the best approach presently possible and is a major step forward compared to national risk assessments performed in the past.

This issue needs to be taken into consideration when making national comparisons since the level of detail in food description will vary between surveys. Therefore, compromises are needed to be made between loss of precision caused by including as many countries as possible or improved accuracy but only within those countries that have highly detailed food descriptions. Additionally, future exposure assessment studies should focus on the development of a total diet study based on the core foods method which allows to get contamination data more in line with food really consumed.

Overall, the authors believe that they have a positive bias in the calculation method, that is a conservative bias. The reason for this is that the occurrence values are often based on targeted sampling of problem products that will influence the overall mean upwards. As described in the manuscript, the authors also did some considerable adjustment to exclude typical adult products rarely consumed by children.

Although the limitations mentioned above should always be considered when interpreting results derived from the EXPOCHI project, this project delivered important data for analyses in the field of exposure assessments in children in Europe, and was a first and valuable step that needed to be done to proceed from a country specific view to a European view. Acknowledging the shortcomings of the current system, EFSA has three main activities under way to address this: (1) the development of a harmonised food description and categorisation system that at least should be able to translate different approaches into a 
404 common output; (2) the dissemination of guidelines developed on how to harmonise food 405 consumption data collection; (3) and finally the development of a guideline for a total diet 406 study approach to get baseline occurrence data. However, these steps are part of a long407 term strategy that will not happen overnight.

\section{$408 \quad$ Conclusion}

409 In this paper we describe two food categorisation methodologies, one for contaminants 410 and one for food colours. The difficulties associated with the creation of a single food 411 categorisation system for several heterogeneous food consumption databases, and possible 412 solutions, were highlighted. The work performed illustrates that food categorisation systems 413 differ depending on the compound under study and that the categorisation work is influenced 414 by the level of detail present in the food consumption databases. Without good planning of 415 objectives for food consumption studies and effort devoted to concerted food categorisation 416 activities in places where occurrence data are produced or collected, the considerable lose of 417 information and higher uncertainty of exposure assessment have to be expected. 418 Nevertheless, the developed systems are an important step forward to reach the goal of a 419 pan-European food categorisation system to perform harmonised exposure assessments at 420 a European level. The best way forward will be by means of a common categorization 421 system based on hierarchical systems for both, food consumption and also concentration 422 data.

\section{Acknowledgments}

425 The project was funded by the European Food Safety Authority (EFSA grant under the Call 426 of proposals CFP/EFSA/DATEX/2008/01). We would like to thank the people from EFSA and 427 the FACET project for their advice and input when setting up the categorisation systems. 428 The dieticians of the Department of Public Health from the Ghent University (Mieke De 429 Maeyer and Mia Bellemans) are acknowledged for their help and support for this work. 


\section{References}

Boon PE, Ruprich J, Petersen A, Moussavian S, Debegnach F, van Klaveren JD. 2009. Harmonisation of food consumption data format for dietary exposure assessments of chemicals analysed in raw agricultural commodities. Food Chem Tox 47: 2883-2889.

Codex Alimentarius Commission. Codex General Standard for Food Additives (updated up to the 32nd session of the Codex Alimentarius Commission) [Internet]. 2009. Available at: http://www.codexalimentarius.net/gsfaonline/index.html

EFSA. 2006. Opinion of the Scientific Panel on contaminants in the food chain on a request from the Commission related to ochratoxin A in food. EFSA Journal 365: 1-56. Available at: http:// www.efsa.europa.eu

EFSA. 2008. Guidance Document for the use of the Concise European Food Consumption Database in Exposure Assessment. EFSA/DATEX/2008/01 [Internet]. Available at: http://www.efsa.europa.eu/en/datex/datexfooddb.htm

EFSA. 2009a. General principles for the collection of national food consumption data in the view of a pan-European dietary survey. EFSA Journal 2009; 7(12):1435. Available at: http://www.efsa.europa.eu

EFSA. 2009b. Panel on Contaminants in the Food Chain (CONTAM). Scientific opinion on arsenic in food. EFSA Journal 7: 1-198. Available at: http://www.efsa.europa.eu

EFSA. 2009c. Scientific Opinion of the Panel on Contaminants in the Food Chain on a request from the European Commission on cadmium in food. EFSA Journal 980: 1-139. Available at: http://www.efsa.europa.eu

EFSA. 2010. Scientific Opinion of the Panel on Contaminants in the Food Chain on a request from the European Commission on lead in food. EFSA Journal 8: 1570. Available at: http://www.efsa.europa.eu

Enghardt-Barbieri H, Pearson M, Becker W. 2006. Riksmaten - barn 2003. Livsmedels - och näringsintag bland barn i Sverige (with a summary in English). Uppsala: Livsmedelsverket.

European Commission. 1994. European Parliament and Council Directive 94/36/EC of 30 June 1994 on colours for use in foodstuffs. Official Journal of the European Communities L 237/13.

European Commission. 2004. Reports on Tasks for Scientific Cooperation (SCOOP) Task 3.2.11. Assessment of the dietary exposures to arsenic, cadmium, lead an mercury of the population of the EU Member States Directorate General Health and Consumer Protection [Internet]. Available at: http://ec.europa.eu/food/food/chemicalsafety/contaminants/scoop_3-211_heavy_metals_report_en.pdf. 
Huybrechts I, Matthys C, Pynaert I, De Maeyer M, Bellemans M, De Geeter H, De Henauw S. 2008. Flanders preschool dietary survey: rationale, aims, design, methodology, and population characteristics. Arch Public Health 66:5-25.

Huybrechts I, Sioen I, Boon PE, Ruprich J, Lafay L, Turrini A, Pilar A, Hirvonen T, De Neve M, Arcella D, Moschandreas J, Westerlund A, Lourdes RB, Hilbig A, Papoutsou S, Christensen T, Oltarzewski M, Virtanen S, Rehurkova I, Azpiri MA, Sette S, Kersting Mathilde, Walkiewicz A, Serra-Majem L, Volatier JL, Trolle E, Tornaritis M, Busk L, Kafatos AG, Fabiansson S, De Henauw S, van Klaveren JD. 2010. Dietary Exposure Assessments for Children in Europe (the EXPOCHI project): rationale, methods and design. Arch Public Health, Submitted.

Leclercq C, Arcella D, Piccinelli R, Sette S, Le Donne C, Turrini A. 2010. The Italian National Food Consumption Survey INRAN-SCAI 2005-06. Main results in terms of food consumption. Public Health Nutr 12(12):2504-2532.

Møller A, Ireland J. 2008. LanguaL 2008 - The LanguaL Thesaurus. EuroFIR Technical Report D1.8.21b. LanguaL European Technical Committee and the EuroFIR Consortium [Internet]. Available from: http://www.eurofir.org/eurofir/Downloads/LanguaL/LanguaL2008/LanguaL\%202 008\%20Thesaurus.pdf

Oldring PKT, Castle L, Franz R. 2009. Exposure to Substances from Food Contact Materials and an Introduction to the FACET Project. Deutsche Lebensmittel-Rundschau 105(8):501-507.

Ruprich J, Dofkova M, Rehurkova I, Slamnenikova E, Resova D. 2006. Individual food consumption - the national study SISP04 [Internet]. Prague: CHFCH NIPH. Available from: http://www.chpr.szu.cz/spotrebapotravin.htm

Turrini, A. 1999. "Food coding in nutritional surveys." Pp. 361-366 in Classification and Data Analysis: Theory and Application. Proceedings of the Biannual Meeting of the Classification Group of Società Italiana di Statistica (SIS) Pescara July 3-4 1997. Edited by M. Vichi and O. Opitz. Berlin Heidelberg: Springer-Verlag. 
499

500 Figure Caption:

501

502 Figure 1. Example of the layout of the main food group 'eggs and egg products, including 503 four subgroups on the level of SG1 and two subgroups on the level of SG2 when $504 \quad$ considering SG1 $=10.1$ (i.e. 'fresh eggs') 


\section{Chapter 10}

\section{Eggs and egg products}

If more details are available for the food items in $M G=10$ : eggs and egg products, go further with this chapter.

If more details are available for food items with a "MG" $=10$, they should be checked for the following characteristics:

- $\quad$ Fresh eggs

$\rightarrow 10.1$

- Egg products produced from fresh eggs: liquid, frozen or dried

$\rightarrow 10.2$

- $\quad$ Preserved eggs e.g. salt-cured, alkaline treated

$\rightarrow 10.3$

- Egg-based dessert

If no more details are available: the final code is $M G=10$

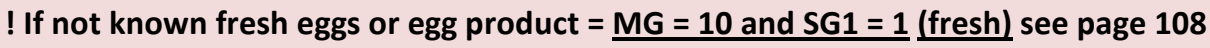

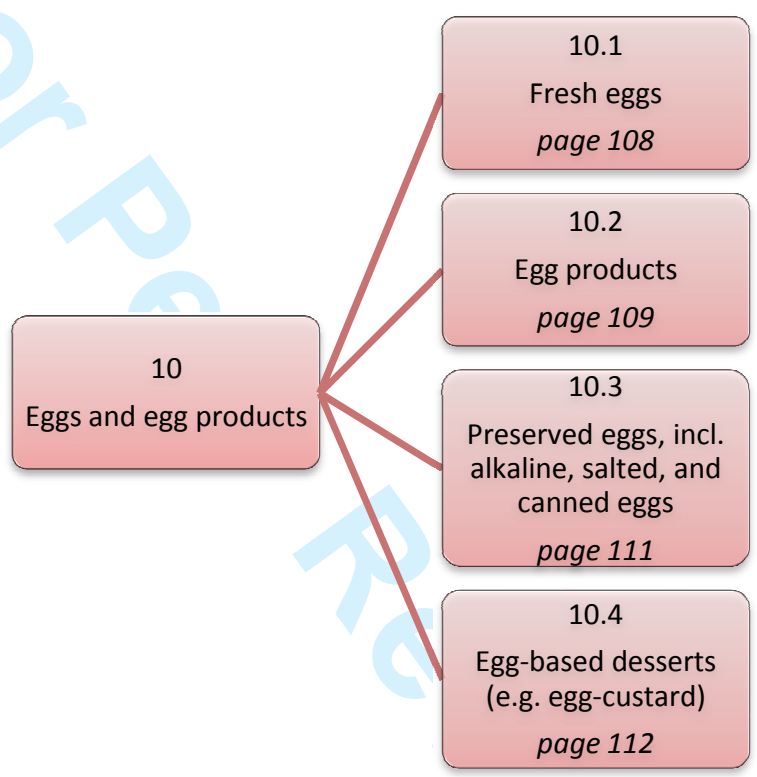

\subsection{Fresh eggs:}

$\rightarrow$ Fresh in-shell eggs are not expected to contain additives. However, colours may be used for decorating, dyeing or stamping the exterior surfaces of shell eggs.

Variable MG $=10$

Variable SG1 = 1

If more details are available for food items that meet the definition of " 10.1 ", they should be checked for the following characteristics:

- If known from indoor reared hens:

$\rightarrow 10.1 .1$

- If known from outdoor reared hens:

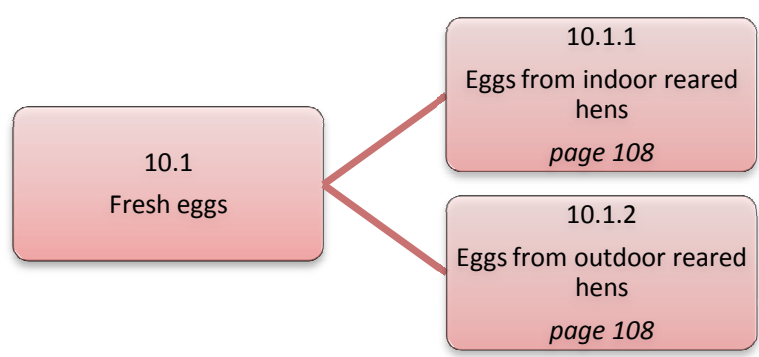

10.1.1 Eggs from indoor reared hens

$\rightarrow$ Hens reared in battery cages 
Table 1. Food groups used for the classification of food items to assess the exposure to lead, chromium and selenium

\begin{tabular}{|c|c|}
\hline MG & Main group \\
\hline 1 & $\begin{array}{l}\text { Dairy products and analogues (incl. dairy based ices), excluding products of food } \\
\text { category "2. Fats and oils, and fat emulsions" e.g. butter }\end{array}$ \\
\hline 2 & Fats, oils and fat emulsions (incl. imitation milks) \\
\hline 3 & Edible ices (excl. dairy based ices) \\
\hline 4 & $\begin{array}{l}\text { Fruits and vegetables (including mushrooms and fungi, roots and tubers, pulses } \\
\text { and legumes, and aloe vera), seaweeds, and nuts and seeds }\end{array}$ \\
\hline 5 & Confectionary \\
\hline 6 & $\begin{array}{l}\text { Cereals and cereal products (cereal grains, tubers, roots, pulses and legumes) } \\
\text { (no bakery wares) }\end{array}$ \\
\hline 7 & Bakery wares \\
\hline 8 & Meat, meat products, poultry and game \\
\hline 9 & $\begin{array}{l}\text { Fish, fish products, molluscs, cephalopods, crustaceans and echinoderms } \\
\text { (MCCE) }\end{array}$ \\
\hline 10 & Eggs and egg products \\
\hline 11 & Sweeteners (incl. honey) \\
\hline 12 & Salt, spices, soups, sauces, salads and protein products \\
\hline 13 & Foodstuff intended for particular nutritional uses \\
\hline 14 & Beverages (excl. dairy products, imitation milks) \\
\hline 15 & Ready-to-eat savouries \\
\hline 16 & Composite foods \\
\hline 17 & Vegetarian meat and fish substitutes \\
\hline 18 & Miscellaneous - foods that cannot be placed in categories \\
\hline
\end{tabular}


3

Table 2. The special codes used for the classification of food items to assess the exposure to lead, chromium and selenium

4

\begin{tabular}{|c|c|}
\hline Special code & Component or physical state \\
\hline 1 & Fruit (filling) \\
\hline 2 & Nuts/seeds (filling) (incl. coconut) \\
\hline 3 & Vegetables (incl. olives) \\
\hline 4 & Pulses/legumes \\
\hline 5 & Chocolate (filling) \\
\hline 6 & Dairy (filling) \\
\hline 71 & Powdered form \\
\hline 72 & Concentrated form \\
\hline 73 & Dissolved from powder or concentrate / Original form \\
\hline 8 & No filling / no pieces \\
\hline 91 & Fish \\
\hline 92 & 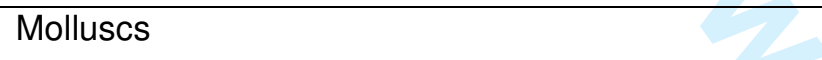 \\
\hline 93 & Crustaceans \\
\hline 94 & Cephalopods \\
\hline 95 & Echinoderm \\
\hline 96 & Reptiles: e.g. crocodile, snake \\
\hline 97 & Amphibian: e.g. frog \\
\hline 900 & Soy \\
\hline 999 & Not known \\
\hline
\end{tabular}

5 
Table 3. The communal food groups used in the food categorisation system for lead, chromium and selenium to link food consumption data to occurrence

7 data of these chemicals combined with the percentage of food items per food group for four different countries

\begin{tabular}{|c|c|c|c|c|c|}
\hline $\begin{array}{l}\text { Communal food } \\
\text { group }\end{array}$ & Name & $\begin{array}{l}\text { Belgium (\%); } \\
n=1056\end{array}$ & $\begin{array}{c}\text { Italy }(\%) \\
n=1530\end{array}$ & $\begin{array}{c}\text { Sweden }(\%) \\
n=1548\end{array}$ & $\begin{array}{l}\text { Czech Republic } \\
\text { (\%); } n=515\end{array}$ \\
\hline 1 & $\begin{array}{l}\text { Composed foods: Cereal based mixed dishes and cereal-based } \\
\text { desserts }\end{array}$ & 4.64 & 0.33 & 5.56 & 1.55 \\
\hline 2 & Vegetables excl. dried vegetables & 11.46 & 4.31 & 11.95 & 10.29 \\
\hline 3 & Nuts and seeds & 1.61 & 1.50 & 1.03 & 2.33 \\
\hline 5 & Chocolate and chocolate products & 3.50 & 1.44 & 1.29 & 2.14 \\
\hline 6 & Fruit excl. dried fruit & 4.92 & 2.88 & 6.85 & 7.38 \\
\hline 7 & Dried fruit & 0.38 & 0.39 & 0.39 & 0.78 \\
\hline 8 & Fresh and dried herbs, spices, seasonings and condiments & 0.00 & 0.92 & 0.58 & 4.47 \\
\hline 11 & $\begin{array}{l}\text { Sugar, sweeteners and sugar products (e.g. sugar based confectionery, } \\
\text { chewing gum and decorations) }\end{array}$ & 1.89 & 8.04 & 1.81 & 2.33 \\
\hline 12 & Fats, oils and fat emulsions (also e.g. rice milk (no soy milk)) & 4.92 & 2.29 & 2.20 & 2.52 \\
\hline 13 & Composed foods: Meat based mixed dishes & 0.85 & 0.13 & 4.01 & 0.97 \\
\hline 14 & Composed foods: Fish based mixed dishes & 0.47 & 0.00 & 1.29 & 0.19 \\
\hline
\end{tabular}




\begin{tabular}{|c|c|c|c|c|c|}
\hline 15 & Dried vegetables & 0.00 & 0.13 & 0.00 & 0.39 \\
\hline 16 & Pulses and legumes & 0.76 & 0.85 & 1.29 & 0.78 \\
\hline 17 & Soy milk and soy based dessert & 1.80 & 0.52 & 0.13 & 0.00 \\
\hline 18 & Milk and dairy drinks & 3.69 & 1.70 & 1.36 & 1.36 \\
\hline 19 & Cheese & 3.98 & 4.58 & 2.39 & 3.30 \\
\hline 20 & Dairy based products & 4.64 & 4.38 & 4.52 & 2.33 \\
\hline 21 & Salt & 0.09 & 0.00 & 0.06 & 0.19 \\
\hline 22 & Fish & 2.27 & 3.40 & 3.94 & 5.24 \\
\hline 23 & Molluscs & 0.28 & 0.26 & 0.19 & 0.19 \\
\hline 24 & Cephalopods & 0.00 & 0.20 & 0.13 & 0.00 \\
\hline 25 & Crustaceans & 0.09 & 0.26 & 0.78 & 0.39 \\
\hline 26 & Other seafood (echinoderms) & 0.00 & 0.07 & 0.00 & 0.00 \\
\hline 27 & Beer and malt beverages & 0.38 & 0.13 & 0.13 & 0.39 \\
\hline 28 & Wine and substitutes & 0.19 & 0.52 & 0.06 & 0.78 \\
\hline 29 & Other alcoholic beverages & 0.00 & 0.26 & 0.06 & 1.94 \\
\hline 30 & Fruit juices and nectars. & 1.61 & 3.99 & 1.29 & 0.19 \\
\hline 31 & Vegetable juices and nectars & 0.09 & 0.00 & 0.06 & 0.19 \\
\hline 32 & Soft drinks and edible ices & 3.79 & 1.76 & 2.91 & 1.17 \\
\hline
\end{tabular}




\begin{tabular}{|c|l|c|c|c|}
\hline 33 & $\begin{array}{l}\text { Cereals and cereal products (no cereal based desserts or cereal based } \\
\text { mixed dishes) }\end{array}$ & 18.84 & 18.37 & 15.63 \\
\hline 34 & Other food for special dietary uses & 0.00 & 0.26 & 0.00 \\
\hline 35 & $\begin{array}{l}\text { Infant formulae, follow up formulae, food for young children and infant } \\
\text { formulae and follow up formulae for medical purposes }\end{array}$ & 0.85 & 3.59 & 0.90 \\
\hline 37 & Miscellaneous foods/products & 6.63 & 2.09 & 9.17 \\
\hline 38 & Liver and kidney & 0.47 & 0.59 & 0.58 \\
\hline 39 & Offals except liver and kidney & 0.09 & 1.44 & 0.84 \\
\hline 40 & Types of vegetarian substitutes for meat and fish & 0.66 & 0.33 & 0.26 \\
\hline 41 & Fresh meat & 7.39 & 2.94 & 5.49 \\
\hline 42 & Processed meat & 2.56 & 2.55 & 5.68 \\
\hline 44 & Coffee and tea in liquid form & 1.33 & 1.11 & 0.19 \\
\hline 45 & Eggs & 0.57 & 0.52 & 0.63 \\
\hline
\end{tabular}


9 Table 4. Food groups used for the classification of food items to assess the exposure to food colours 10 (exc. lycopene)

\begin{tabular}{|c|c|c|}
\hline Code & Food group name & EXPOCHI* \\
\hline 0 & No food colour allowed & $\mathrm{X}$ \\
\hline 1 & Non-alcoholic flavoured drinks & $\mathrm{X}$ \\
\hline 2 & Candied fruits \& vegetables, Fruit Mustard & $\mathrm{X}$ \\
\hline 3 & Preserves of red fruits & $\mathrm{X}$ \\
\hline 4 & Confectionery & $\mathrm{X}$ \\
\hline 5 & Decorations \& coatings & $\mathrm{X}$ \\
\hline 6 & Fine bakery wares (e.g. viennoiserie, biscuits, cakes, wafers) & $\mathrm{X}$ \\
\hline 7 & Edible ices & $\mathrm{X}$ \\
\hline 8 & Flavoured processed cheese & $\mathrm{X}$ \\
\hline 9 & Desserts inc. flavoured milk products & $\mathrm{X}$ \\
\hline 10 & Sauces, seasonings (e.g. curry powder, tandoori), pickles, relishes, chutney, piccalilli & $\mathrm{X}$ \\
\hline 11 & Mustard & $\mathrm{X}$ \\
\hline 12 & Fish paste and crustacean paste & $\mathrm{X}$ \\
\hline 13 & Pre-cooked crustaceans & $\mathrm{X}$ \\
\hline 14 & Salmon substitutes & $\mathrm{X}$ \\
\hline 15 & Surimi & $\mathrm{X}$ \\
\hline 16 & Fish roe & $\mathrm{X}$ \\
\hline 17 & Smoked fish & $\mathrm{X}$ \\
\hline 181 & Other savoury snack products and savoury peanuts, nuts or hazelnuts & $\mathrm{X}$ \\
\hline 182 & $\begin{array}{l}\text { Snacks: dry, savoury potato, cereal or starch-based snack products: extruded or } \\
\text { expanded savoury snack products }\end{array}$ & $\mathrm{X}$ \\
\hline 19 & Edible cheese rind and edible casings & $\mathrm{X}$ \\
\hline 20 & Complete formulae for weight control intended to replace total daily food intake or an & \\
\hline
\end{tabular}




\begin{tabular}{|c|c|c|}
\hline Code & Food group name & EXPOCHI* \\
\hline & individual meal & \\
\hline 21 & Complete formulae and nutritional supplements for use under medical supervision & \\
\hline 22 & Liquid food supplements/dietary integrators & \\
\hline 23 & Solid food supplements/dietary integrators & \\
\hline 24 & Soups & $\mathrm{X}$ \\
\hline 25 & Meat and fish analogues based on vegetable proteins & $\mathrm{X}$ \\
\hline 26 & $\begin{array}{l}\text { Spirituous beverages (inc. products less than 15\% alcohol by volume), except any } \\
\text { mentioned in Schedule } 2 \text { or } 3\end{array}$ & \\
\hline 27 & $\begin{array}{l}\text { Aromatized wines, aromatized wine-based drinks and aromatized wine-product } \\
\text { cocktails as mentioned in Reg 1601/91, except any mentioned in Schedule } 2 \text { or } 3\end{array}$ & \\
\hline 28 & $\begin{array}{l}\text { Fruit wines (still or sparkling), Cider (except cider bouche) and perry and aromatized } \\
\text { fruit wines }\end{array}$ & \\
\hline 29 & Malt bread & $\mathrm{X}$ \\
\hline 30 & Beer, Cider bouche & \\
\hline 31 & Butter (including reduced-fat butter and concentrated butter) & $\mathrm{X}$ \\
\hline 32 & Margarine, minarine, other fat emulsions, and fats essentially free from water & $\mathrm{X}$ \\
\hline 33 & Sage Derby cheese & $\mathrm{X}$ \\
\hline 34 & Ripened Orange, Yellow and broken-white cheese; unflavoured processed cheese & $\mathrm{X}$ \\
\hline 35 & Red Leicester cheese; Mimolette cheese & $\mathrm{X}$ \\
\hline 36 & Morbier cheese & $\mathrm{X}$ \\
\hline 37 & Red marbled cheese & $\mathrm{X}$ \\
\hline 38 & Vinegar & $\mathrm{X}$ \\
\hline 39 & $\begin{array}{l}\text { Whisky, Whiskey, grain spirit (other than ....), wine spirit, rum, Brandy, Weinbrand, } \\
\text { grape marc, grape marc spirit (other than ...) Grappa invecchiata, Bazaceira velha as } \\
\text { mentioned in Reg (EEC) No. 1601/91 }\end{array}$ & \\
\hline 40 & $\begin{array}{l}\text { Aromatized wine-based drinks (except bitter soda) and aromatized wines as mentioned } \\
\text { in Reg (EEC) No. 1601/91 }\end{array}$ & \\
\hline 41 & Americano & \\
\hline
\end{tabular}




\begin{tabular}{|c|c|c|}
\hline Code & Food group name & EXPOCHI $^{*}$ \\
\hline 42 & Bitter soda, bitter wine as mentioned in Reg (EEC) No. 1601/91 & \\
\hline 43 & Liqueur wines and quality liqueur wines produced in specified regions & \\
\hline 44 & Vegetables in vinegar, brine or oil (excluding olives) & $\mathrm{X}$ \\
\hline 45 & Extruded, puffed and/or fruit-flavoured breakfast cereals & $\mathrm{X}$ \\
\hline 46 & Fruit-flavoured breakfast cereals & $\mathrm{X}$ \\
\hline 47 & $\begin{array}{l}\text { Jams, jellies, and marmalades as mentioned in Directive 79/693/EEC and other similar } \\
\text { fruit preparations including low-calorie products }\end{array}$ & $\mathrm{X}$ \\
\hline 48 & Sausages, pates and terrines & $\mathrm{X}$ \\
\hline 49 & Luncheon meat & $\mathrm{X}$ \\
\hline 50 & $\begin{array}{l}\text { Breakfast sausages with a minimum cereal content of } 6 \% \text {; Burger meat with a minimum } \\
\text { vegetable and/or cereal content of } 4 \%\end{array}$ & $\mathrm{X}$ \\
\hline 51 & Chorizo sausage; Salchichon & $\mathrm{X}$ \\
\hline 52 & Sobrasada & $\mathrm{X}$ \\
\hline 53 & Pasturmas (edible external coating) & $\mathrm{X}$ \\
\hline 54 & Dried potato granules and flakes & $\mathrm{X}$ \\
\hline 55 & Processed mushy and garden peas (canned) & $\mathrm{X}$ \\
\hline 56 & Aperitif wines, spirit drinks including products with less than $15 \%$ alcohol by volume & \\
\hline 57 & Cocktail cherries and candied cherries & $\mathrm{X}$ \\
\hline 58 & Bigarreaux cherries in syrup and in cocktails & $\mathrm{X}$ \\
\hline 59 & Kippers & $\mathrm{X}$ \\
\hline 60 & External coating of sugar confectionery for the decoration of cakes and pastries & $\mathrm{X}$ \\
\hline 61 & External coating of confectionery & $\mathrm{X}$ \\
\hline 62 & Decoration of chocolates & $\mathrm{X}$ \\
\hline 63 & Liqueurs & \\
\hline 64 & Liqueurs, including fortified beverages with less than $15 \%$ alcohol by volume & \\
\hline 65 & Edible cheese rind & $\mathrm{X}$ \\
\hline
\end{tabular}


1

2

3

4

5

6

7

8

9

10

11

12

13

14

15

16

17

18

19

20

21

\begin{tabular}{|c|c|c|}
\hline Code & Food group name & EXPOCHI* \\
\hline 66 & Saucisses de Strasbourg & $\mathrm{X}$ \\
\hline 67 & All other foodstuffs & $\mathrm{X}$ \\
\hline 68 & Meat and fish products & $\mathrm{X}$ \\
\hline 69 & Canned meat products & $\mathrm{X}$ \\
\hline 70 & Liver pate & $\mathrm{X}$ \\
\hline 71 & Roast beef & $\mathrm{X}$ \\
\hline 72 & Meat products (including roast beef, cutlet, ready meals) & $\mathrm{X}$ \\
\hline 73 & Liquid egg products & $\mathrm{X}$ \\
\hline 74 & Milk and dairy based drinks & $\mathrm{X}$ \\
\hline 75 & Fruit and vegetables canned, frozen, etc & $\mathrm{X}$ \\
\hline 76 & Dairy products & $\mathrm{X}$ \\
\hline 77 & Noodles & $\mathrm{X}$ \\
\hline 78 & Ready meals & $\mathrm{X}$ \\
\hline 79 & Delicatessen salads & $\mathrm{X}$ \\
\hline 80 & Processed potato products & $\mathrm{X}$ \\
\hline 81 & Liquid dough & $\mathrm{X}$ \\
\hline 82 & Milk and cream analogues & $\mathrm{X}$ \\
\hline
\end{tabular}

11 "Food groups that were considered within the EXPOCHI project are marked with the sign "X". 
Table 5. Food groups used for the classification of food items to assess the exposure to lycopene

\begin{tabular}{|c|c|c|c|c|c|}
\hline Code & Food group name & $\begin{array}{l}\text { Belgium } \\
\qquad \%) \\
\mathrm{n}=1056\end{array}$ & $\begin{array}{c}\text { Italy (\%) } \\
n=1530\end{array}$ & $\begin{array}{l}\text { Sweden } \\
\qquad \%) \\
n=1548\end{array}$ & $\begin{array}{l}\text { Czech } \\
\text { Republic } \\
(\%) ; n=515\end{array}$ \\
\hline 0 & No lycopene & 60.61 & 69.54 & 68.73 & 77.48 \\
\hline 19 & Non-alcoholic flavoured drinks & 3.60 & 1.70 & 2.33 & 1.17 \\
\hline 20 & Candied fruits and vegetables, Fruit Mustard & 0.19 & 0.20 & 1.23 & 0.58 \\
\hline 21 & Confectionery & 0.95 & 5.88 & 1.29 & 1.36 \\
\hline 22 & Decorations and coatings & 0.00 & 0.00 & 0.06 & 0.00 \\
\hline 23 & $\begin{array}{l}\text { Fine bakery wares (e.g. viennoiserie, biscuits, } \\
\text { cakes and wafers) }\end{array}$ & 9.19 & 5.95 & 6.40 & 4.47 \\
\hline 24 & Edible ices & 0.19 & 0.07 & 0.58 & 0.00 \\
\hline 25 & Flavoured processed cheese & 0.57 & 0.52 & 0.39 & 0.78 \\
\hline 26 & Desserts including flavoured milk products & 6.34 & 3.59 & 5.94 & 2.33 \\
\hline 27 & $\begin{array}{l}\text { Sauces, seasonings (for example, curry } \\
\text { powder, tandoori), pickles, relishes, chutney } \\
\text { and picalilli }\end{array}$ & 2.37 & 0.52 & 3.75 & 3.30 \\
\hline 28 & $\begin{array}{l}\text { Jams jellies and marmalades as mentioned in } \\
\text { directive } 79 / 693 / E C \text { and similar fruit preps }\end{array}$ & 1.42 & 0.65 & 1.16 & 0.78 \\
\hline 29 & Fish paste and crustacean paste & 0.00 & 0.00 & 0.06 & 0.39 \\
\hline 30 & Pre-cooked crustaceans & 0.09 & 0.07 & 0.13 & 0.00 \\
\hline 31 & Salmon substitutes & 0.00 & 0.00 & 0.00 & 0.00 \\
\hline 32 & Surimi & 0.00 & 0.00 & 0.00 & 0.00 \\
\hline 33 & Fish roe & 0.00 & 0.00 & 0.13 & 0.19 \\
\hline 34 & Smoked fish & 0.38 & 0.07 & 0.39 & 0.39 \\
\hline 35 & $\begin{array}{l}\text { Snacks: extruded or expanded savoury snack } \\
\text { products }\end{array}$ & 1.33 & 0.13 & 0.90 & 0.97 \\
\hline 36 & $\begin{array}{l}\text { Snacks: other savoury snack products and } \\
\text { savoury coated nuts }\end{array}$ & 0.38 & 0.65 & 0.26 & 0.39 \\
\hline 37 & Edible cheese and edible casings & 0.00 & 0.00 & 0.00 & 0.00 \\
\hline 38 & $\begin{array}{l}\text { Complete formulae for weight control } \\
\text { intended to replace total daily intake or an }\end{array}$ & 0.00 & 0.00 & 0.00 & 0.00 \\
\hline
\end{tabular}




\begin{tabular}{|c|c|c|c|c|c|}
\hline & individual meal & & & & \\
\hline 39 & $\begin{array}{l}\text { Complete formulae and nutritional } \\
\text { supplements for use under medical } \\
\text { supervision }\end{array}$ & 0.00 & 0.00 & 0.00 & 0.00 \\
\hline 40 & Liquid food supplements / dietary integrators & 0.00 & 0.00 & 0.00 & 0.00 \\
\hline 41 & Solid food supplements / dietary integrators & 0.00 & 0.00 & 0.00 & 0.00 \\
\hline 42 & $\begin{array}{l}\text { Meat and fish analogues based on vegetable } \\
\text { proteins }\end{array}$ & 0.47 & 0.33 & 0.19 & 0.19 \\
\hline 43 & $\begin{array}{l}\text { Spirituous beverages (excluding products } \\
<15 \% \text { alcohol by volume) except those } \\
\text { mentioned in Annex II or III }\end{array}$ & 0.00 & 0.00 & 0.00 & 0.00 \\
\hline 44 & $\begin{array}{l}\text { Aromatized wines, aromatized wine based } \\
\text { drinks and aromatized wine product cocktails } \\
\text { as mentioned in Regulation (EEC) No } 160 \ldots \\
\text { except those mentioned in Annex II or III }\end{array}$ & 0.00 & 0.00 & 0.00 & 0.00 \\
\hline 45 & $\begin{array}{l}\text { Fruit wine (still or sparkling); Cider (except } \\
\text { cidre bouche) and perry; Aromatized fruit } \\
\text { wines }\end{array}$ & 0.00 & 0.00 & 0.00 & 0.00 \\
\hline 46 & $\begin{array}{l}\text { Fruit/vegetable juice-based drinks (including } \\
\text { concentrates) }\end{array}$ & 1.61 & 3.46 & 1.10 & 0.39 \\
\hline 47 & $\begin{array}{l}\text { Drinks intended to meet the expenditure of } \\
\text { intense muscular effort especially for } \\
\text { sportsmen }\end{array}$ & 0.00 & 0.00 & 0.00 & 0.00 \\
\hline 49 & Breakfast cereals & 4.36 & 2.94 & 1.42 & 0.97 \\
\hline 50 & Fats and dressings & 4.83 & 1.96 & 1.94 & 2.52 \\
\hline 51 & Bread (including crispy breads) & 1.14 & 1.76 & 1.61 & 1.36 \\
\hline
\end{tabular}

